\title{
Does Migration Encourage Human Capital Formation in Labor-Sending Country?
}

\author{
Akira Shimada \\ Nagasaki University, Nagasaki, Japan
}

\begin{abstract}
This study investigates the effects of migration possibilities on the demand for education and human capital formation in the labour-sending country. The paper assumes that workers have to pay a pecuniary cost privately to receive education under budget constraints. It was found that higher migration possibilities result in an increase in the number of workers who demand education due to increases in its return. However, these workers lower the individual demand for education due to price increases. When the education supply is insufficient, higher migration possibilities may lower average human capital; that is, a brain drain may occur. This contrasts with the usual argument that emphasises the positive effect of migration possibilities. Restrictive immigration policies were found not to be completely detrimental to labour-sending countries since such policies may enhance the human capital formation.
\end{abstract}

JEL Classifications: F22, I22, J24, O15

\footnotetext{
* Corresponding Author: Akira Shimada; Faculty of Economics, Nagasaki University, 4-2-1, Katafuchi, Nagasaki City, 850-8506, Japan; Tel: +81 958206353, E-mail: shimada@nagasaki-u.ac.jp.

Acknowledgements: This paper was presented at the 10th International Conference of the Japan Economic Policy Association held at Kwansei Gakuin University, Kobe, in November 2011; the 2011 International Symposium on Contemporary Labor Economics held at Wang Yanan Institute for Studies in Economics, Xiamen University, Xiamen, in December 2011; and the 11th Annual Conference of the European Economics and Finance Society held at Koç University, Istanbul, in June 2012. I am grateful to Dipak Basu and the participants at these meetings for their valuable comments. I would also like to express my sincere gratitude to the anonymous referees for their significant comments. Financial support by the Japan Society for the Promotion of Science is gratefully acknowledged. Needless to say, any remaining errors are my responsibility.
} 
Key words: Migration, Heterogeneous Workers, Education Market, Human Capital Formation, Brain Drain, Brain Gain

\section{Introduction}

This paper investigates the effects of migration possibilities to a foreign (labourreceiving) country on the demand for education and human capital formation in a home (labour-sending) country when workers are heterogeneous in their innate ability and have to pay a pecuniary cost by themselves to receive education. Unlike previous analyses, this paper shows that due to the increase in the cost of education and a subsequent decrease in the return on education, migration possibilities to the foreign country do not necessarily enhance human capital formation in the home country. From this study's results, the positive effect of the foreign country's restrictive immigration policy on the home country's human capital can be derived.

With an increase in the number of workers who migrate internationally, many labour-receiving developed countries have become stringent in accepting migrants, as argued by Boeri and Brücker (2005), Facchini and Mayda (2008), and Felbermayr et al. (2010). ${ }^{1}$ This trend poses a serious threat to labour-sending developing countries because they are heavily dependent on remittances sent by migrants. ${ }^{2}$

In addition, many labour-receiving developed countries have become selective they prefer to accept skilled migrants. ${ }^{3}$ For example, the Australian Government (2011) has decided to implement the new Skilled Migrant Selection Register, SkillSelect, to accept migrants who are skilled and needed in specific occupational groups. Such a policy encourages the outflow of skilled workers, who are also markedly scarce in these countries, from developing countries. Other evidence of significant skilled worker outflows released by the World Bank (2011) includes the high emigration rate (over 80 percent) for the tertiary-educated population of Guyana, Granada, Jamaica, St. Vincent, the Grenadines, and Haiti in 2000. Moreover, utilising the data of Docquier

\footnotetext{
${ }^{1}$ According to the World Bank (2011), the stock of migrants as of 2010 is 215.8 million, accounting for 3.2 percent of the world population.

${ }^{2}$ It is widely accepted that remittances sent by migrants are an important financial resource for these countries. See Shimada (2010, 2011a) for the effects of sending and receiving fees on the amount of remittances and the role of altruism in sending and spending remittances.

${ }^{3}$ Huber et al. (2010) reveal that highly-skilled migrants play a positive role in productivity development in the so-called skill intensive industries.
} 
and Marfouk (2006), Grogger and Hanson (2011) show that emigrants are, in general, positively selected in terms of schooling. These observations suggest that many laboursending developing countries are experiencing an outflow of human capital, or a brain drain, due to skilled worker emigration.

Based on these facts, it is argued that labour-sending countries are negatively affected by the restrictive and selective migration policies of labour-receiving developed countries. Previous studies conclude that such migration policies have only negative effects on labour-sending countries.

The effects of emigration on labour-sending countries have long been a very controversial issue. Docquier and Rapoport (2009) divide the controversies into three generations. ${ }^{4}$ Arguments by Grubel and Scott (1966) and Berry and Soligo (1969), which can be included in the first generation, illustrate emigration's positive aspects, assuming a competitive economy. On the other hand, arguments by Bhagwati and Hamada (1974), Hamada and Bhagwati (1975), and Bhagwati and Rodriguez (1975), which can be included in the second generation, emphasise the negative effects, assuming a non-competitive economy.

Recent arguments put forth by Mountford (1997), Stark et al. (1997, 1998, 2009a, b), and Beine et al. (2001, 2008), which can be classified into the third generation, have been gaining popularity.

They derive the positive effects of emigration, and their results are independent of the economy's competitiveness or non-competitiveness. ${ }^{5}$ It is a fact that labour-sending countries lose a portion of their human capital by the outflow of workers; however, migration possibilities increase the return on education. This induces workers to increase demand for education, which enhances human capital formation. Accordingly, workers in labour-sending countries may experience brain gain by the increase in migration possibilities.

As noted by these studies, obtaining education incurs costs. If workers can manipulate working hours, they will reduce their working hours and earnings in order to obtain education. ${ }^{6}$ Such an opportunity cost certainly affects the demand for education and human capital formation.

\footnotetext{
${ }^{4}$ I do not intend to survey the related literature here.

5 According to an empirical analysis by Beine et al. (2011), whether brain gain occurs depends on the labour-sending countries' incomes. In particular, they found that low-income countries experience brain gain, but they found no such evidence in middle-income and high-income countries. Assuming the different types of workers, that is, skilled and unskilled workers, Shimada (2011b) theoretically shows that brain drain and brain gain can occur simultaneously in the labour-sending country.

${ }^{6}$ Stark et al. (1998) explicitly includes an opportunity cost for education in the two-period model.
} 
However, the opportunity cost is not the only cost involved. Workers usually have to pay a pecuniary cost to obtain education. Primary and secondary education is predominantly provided through taxes; however, tertiary education cannot be provided only by taxes. Whether it is optimal for an individual or an economy to finance tertiary education privately or publicly, most individuals generally pay a portion or all of the pecuniary costs. ${ }^{7}$ In fact, the price is established in the education market, and individuals face financing problems when obtaining education. Whether and to what extent individuals can afford the pecuniary cost affects the demand for education and human capital formation. Nevertheless, previous studies have not given appropriate attention to this constraint.

If workers have to privately pay the pecuniary cost for education, they will be sensitive to the education price, which will affect human capital formation. For example, a higher demand for education due to higher migration possibilities and/ or an insufficient domestic supply of education may increase the education price and lower its return. This may reduce the aggregate demand for education. On the other hand, the number of workers who satisfy the budget constraint and demand education may increase with migration possibilities. This may increase the aggregate demand for education. These possible effects have mostly been neglected in previous studies. ${ }^{8}$

Therefore, this study incorporates the education market in the home country and explicitly considers the transaction of education in order to illustrate the effects of migration possibilities on the demand for education and human capital formation through changes in the price of education. In doing so, this study attempts to draw further inferences on brain drain and brain gain due to changes in migration possibilities.

This paper finds that higher migration possibilities increase the education price and reduce the individual demand for education by workers who satisfy the budget constraint; on the other hand, as migration possibilities increase, a larger number of workers satisfy the budget constraint and thus demand education. In the case where the home country cannot provide its residents with education sufficiently, I find that the former negative effect dominates the latter positive effect and that higher migration possibilities hamper human capital formation.

This result contrasts with those of previous studies since it suggests that restrictive

\footnotetext{
See Barr (2004) for a discussion on how higher education should be funded.

${ }^{8}$ The study by Nakajima and Nakamura (2009) is an exception. They build a model which incorporates an educational institute and the education price; their model illustrates that because of the increase in the education price arising from demand by the rich, the poor are gradually excluded from higher education, and consequently, income inequality between the rich and poor expands in the long run.
} 
migration policies adopted today by many labour-receiving developed countries might lead to brain gain of labour-sending developing countries; that is, an increase in the average human capital. Restrictive migration policies reduce the outflow of workers and human capital, which clearly has favourable effects on human capital in labour-sending countries. In addition, through the decrease in the education price, lower migration possibilities increase the individual demand for education, which encourages human capital formation. Favourable effects of restrictive migration polices on human capital formation through the education market have been left uninvestigated by previous studies.

The remainder of this paper is organised as follows: Section II presents a model of a two-country economy with migration possibilities from the home country to the foreign country. I assume that workers in the home country are heterogeneous in their innate ability and that there is an education market in that country. Section III examines the effects of migration possibilities on the demand for education. Section IV examines the effects of migration possibilities on the average human capital of the home country and draws inferences on the outcome of restrictive migration policies on human capital formation. Section V presents the conclusion.

\section{The Model}

I assume that an economy consists of home and foreign countries. Workers in the home country are heterogeneous in their innate ability and live for two periods - the first and second period. They provide labour in both periods, but receive education only in the first period. The productivity in the first period is determined by their innate ability and a fixed amount of publicly-financed education. I assume this education to be one unit, and workers do not have to directly pay for it. They may further receive privately-financed education via self-funding. Privately-financed education is provided in the first period to those who pay for it and gives utility in that period to them, and it increases their productivity only in the second period. Workers in the home country migrate to the foreign country in the second period with probabilities that depend on their amount of privately-financed education. All migrated workers earn higher wages in the foreign country than in the home country.

I incorporate the resource market for human capital formation, that is, the privately- 
financed competitive education market into the home country.

Worker $i$ has innate ability $a_{i}$ that is distributed uniformly between $\varepsilon(>0)$ and $1+\varepsilon$. By receiving one unit of publicly-financed education, innate ability $a_{i}$ is transformed into $a_{i}$ efficiency units of labour in the first period (if workers did not receive publiclyfinanced education, efficiency units of labour would be zero even with positive innate ability). In addition, the worker may demand privately-financed education by $e_{i}(\geq 1)$ and forms human capital by $\ln e_{i}$. This increases the efficiency units of labour to $a_{i}\left(1+\ln e_{i}\right)$ in the second period. If the worker cannot pay for privately-financed education due to a budget constraint, only publicly-financed education is received in the first period. In this case, the efficiency units of labour in the second period are also $a_{i}$.

In order to demand privately-financed education by $e_{i}$, worker $i$ has to bear the pecuniary cost privately by $\bar{c}+p e_{i}$, where $\bar{c}(>0)$ is a constant denoting fixed cost, and $p$ is the price of privately-financed education determined to equalise its demand and supply in that market. In addition, as in Stark et al. (1998), worker $i$ has to give up a portion of the labour supply to receive education. Since the amount of publicly - financed education is given, the larger the amount of privately-financed education, the shorter the first period's working hour is. Accordingly, the working hour can be described as $1-h\left(e_{i}\right)$, where $d h\left(e_{i}\right) / d e_{i}>0$ and $0<h\left(e_{i}\right)<1$.

In the second period, workers in the home country can migrate to the foreign country. In general, workers with higher productivity are more likely to be accepted in the labour-receiving country. This suggests that, in my model, a worker with a larger amount of privately-financed education has higher migration possibilities. Accordingly, worker $i$ has migration possibilities $0<\theta+m\left(e_{i}\right)<1$, where $\theta(>0)$ is a constant and $d m\left(e_{i}\right) / d e_{i}>0 . \theta$ represents migration possibilities that are provided independently of the amount of privately-financed education.

Net earnings of worker $i$ are equal to

$$
a_{i}\left\{1-h\left(e_{i}\right)\right\} w_{H}-\bar{c}-p e_{i}+\rho a_{i}\left(1+\ln e_{i}\right)\left[\left\{\theta+m\left(e_{i}\right)\right\} w_{F}+\left\{1-\theta-m\left(e_{i}\right)\right\} w_{H}\right],
$$

where $w_{F}>w_{H}>0$ are wages per efficiency unit of labour in the foreign and home countries, respectively, and $0<\rho \leq 1$ is the subjective time preference rate. Privatelyfinanced education reduces the first-period wages by $a_{i} h\left(e_{i}\right) w_{H}$, whereas it increases the second-period wages relative to the first period by $\rho a_{i}\left(1+\ln e_{i}\right)\left(w_{F}-w_{H}\right) m\left(e_{i}\right)$. I assume that these two effects offset each other, that is, $-a_{i} h\left(e_{i}\right) w_{H}+\rho a_{i}\left(1+\ln e_{i}\right)\left(w_{F}-w_{H}\right)$ $m\left(e_{i}\right)=0$. Under this assumption, net earnings can be defined as $a_{i} w_{H}-\bar{c}-p e_{i}+\rho a_{i}$ $\left(1+\ln e_{i}\right)\left\{\theta w_{F}+(1-\theta) w_{H}\right\}$. 
Since worker $i$ has to pay the education cost using his/her earnings, this cost must not exceed the earnings, and the net earnings have to be non-negative, that is,

$$
a_{i} w_{H}-\bar{c}-p e_{i}+\rho a_{i}\left(1+\ln e_{i}\right)\left\{\theta w_{F}+(1-\theta) w_{H}\right\}\left(\equiv U_{i}\right) \geq 0
$$

This budget constraint suggests that the cost of education has to be financed by the earnings in the first and second periods. If the first period's earnings are not sufficient to pay for education, the worker borrows money and repays it in the second period. This is not possible if there is no credit market. Accordingly, my model implicitly assumes a credit market. However, in my model, the worker lives only for two periods and there is no succeeding generation to which he/she passes on any debt. As a result, the worker cannot borrow money beyond the second period.

Worker $i$ demands privately-financed education by paying the pecuniary cost to maximise utility $\widetilde{U}$, which is assumed to be the sum of the utility derived from privately-financed education and net earnings

$$
\tilde{U}_{i}=\bar{u}+a_{i} w_{H}-\bar{c}-p e_{i}+\rho a_{i}\left(1+\ln e_{i}\right)\left\{\theta w_{F}+(1-\theta) w_{H}\right\}
$$

where $\bar{u}$ denotes the utility derived from privately-financed education, being a positive constant, larger than $\rho a_{i}\left\{\theta w_{F}+(1-\theta) w_{H}\right\}+\bar{c}$ if $e_{i}>0$, and zero if $e_{i}=0$.

In general, even if a worker satisfies the budget constraint, he/she does not necessarily demand education. However, in my model, from the assumption that privately-financed education gives a fixed utility to those who receive it, a worker whose net earnings are non-negative can attain higher utility by receiving privatelyfinanced education. Therefore, a worker who satisfies the budget constraint always demands privately-financed education. ${ }^{10}$

\footnotetext{
${ }^{9}$ If a worker cannot satisfy the budget constraint, the utility function will take a different form from Equation (1). In such a case, the utility is a constant.

${ }^{10}$ For a worker who satisfies the budget constraint, the difference between the utility derived from taking privately-financed education $\left.U_{i}\right|_{e_{i}>0}$ and the utility derived from not taking such education $\left.U_{i}\right|_{e_{i}=0}$ is $\bar{u}-\bar{c}-p e_{i}+\rho a_{i} l n e_{i}\left\{\theta w_{F}+(1-\theta) w_{H}\right\}$. Subsequently, I derive the individual demand for education as $e_{i}=\rho a_{i}\left\{\theta w_{F}+(1-\theta) w_{H}\right\} / p$ (see Equation 2). As a result, $\left.U_{i}\right|_{e_{i}>0}-\left.U_{i}\right|_{e_{i}=0}=\bar{u}-\bar{c}-\rho a_{i}\left\{\theta w_{F}+(1-\theta) w_{H}\right\}\left(1-\ln e_{i}\right)$. Therefore, if $\bar{u}>\rho a_{i}\left\{\theta w_{F}+(1-\theta) w_{H}\right\}+\bar{c}$, then a worker always prefers to demand privately-financed education.
} 


\section{Effects of Migration Possibilities on Education Demand}

This section examines how migration possibilities affect the demand for privatelyfinanced education by workers in the home country. In particular, I attempt to find out whether the number of workers who satisfy the budget constraint and demand privatelyfinanced education will increase and whether such workers will increase their individual demand with migration possibilities.

I assume that the worker with innate ability $\widetilde{a}$, where $\varepsilon<\widetilde{a}<1+\varepsilon$, satisfies the budget constraint with an equality, $\left.U_{i}\right|_{a_{i}=\widetilde{a}}=0$. Subsequently, I show that by making an assumption on $\bar{c}$, worker $i$ with innate ability $a_{i} \in(\widetilde{a}, 1+\varepsilon]$ satisfies the budget constraint with an inequality, $\left.U_{i}\right|_{\tilde{a}<a_{i} \leq 1+\varepsilon}>0$, and demands privately-financed education. On the other hand, a worker with innate ability $a_{i} \in[\varepsilon, \widetilde{a})$ does not satisfy the budget constraint, $\left.U_{i}\right|_{\varepsilon \leq a_{i}<\widetilde{a}}<0$, and thus cannot demand privately-financed education. $\tilde{a}$ is an endogenous variable affected by $\theta$.

I derive the demand for privately-financed education by the worker with innate ability $a_{i} \in[\widetilde{a}, 1+\varepsilon]$ from $d \widetilde{U}_{i} / d e_{i}=0$. Such a worker demands privately-financed education by

$$
e_{i}=\frac{\rho a_{i}\left\{\theta w_{F}+(1-\theta) w_{H}\right\}}{p}
$$

Worker $i$ demands a larger amount of privately-financed education if the worker is more innately talented or if migration possibilities are higher because such conditions increase the return of such education $\left(\partial e_{i} / \partial a_{i}>0, \partial e_{i} / \partial \theta>0\right)$. Higher price of privatelyfinanced education decreases its demand since the higher price lowers the return on such education $\left(\partial e_{i} / \partial p<0\right)$.

Summing up the individual demand for privately-financed education, the home country's aggregate demand for such education, $D$, is

$$
D=\int_{\widetilde{a}}^{1+\varepsilon}\left[\rho a_{i}\left\{\theta w_{F}+(1-\theta) w_{H}\right\} / p\right] d a_{i}=\frac{\rho\left\{\theta w_{F}+(1-\theta) w_{H}\right\}}{p} \frac{(1+\varepsilon)^{2}-\widetilde{a}^{2}}{2} .
$$

I assume that the home country's aggregate supply of privately-financed education, $S$, is a constant $S=\bar{b}(>0)$. 
To be certain, I can make the supply of privately-financed education dependent on its price and other variables. However, this supply will be inelastic in the short run, since, as suggested by the World Bank (2000), the quantity of effective education is determined not only by the quantity itself, such as the number of teachers or schools but also by the quality, such as the provision of well-designed academic programs - which are difficult to improve in a short period of time. We infer that the supply of privatelyfinanced education is limited in developing countries.

Assuming that the privately-financed education market is competitive, the equilibrium condition, $D=S$, provides us with its equilibrium price

$$
p=\frac{\rho\left\{\theta w_{F}+(1-\theta) w_{H}\right\}}{\bar{b}} \frac{(1+\varepsilon)^{2}-\widetilde{a}^{2}}{2}(\equiv p(\widetilde{a}, \theta)),
$$

where $\tilde{a}$ is given exogenously here (subsequently, I illustrate how it will be affected by $\theta$ ). If $\tilde{a}$ is smaller, that is, if a larger number of workers satisfy the budget constraint and demand privately-financed education, the aggregate demand is larger. As a result, the price is higher $\left(\partial p(\tilde{a}, \theta) / \partial \widetilde{a}\left(\equiv p_{\widetilde{a}}\right)<0\right)$. Higher migration possibilities increase the return on privately-financed education and thereby increase the aggregate demand, leading to the higher price $(\partial p(\widetilde{a}, \theta) / \partial \theta>0)$.

By substituting Equation (3) into Equation (2), worker $i$ 's privately-financed education demand is

$$
e_{i}=\frac{2 \bar{b} a_{i}}{(1+\varepsilon)^{2}-\widetilde{a}^{2}}\left(\equiv e_{i}\left(a_{i}, \tilde{a}\right)\right)
$$

where $\tilde{a}$ is given exogenously here (subsequently, I illustrate how it will be affected by $\theta$ ). A higher innate ability increases the individual demand for privately-financed education since it increases its return $\left(\partial e_{i}\left(a_{i}, \tilde{a}\right) / \partial a_{i}>0\right)$. The larger the $\tilde{a}$, the lower the price is, since a smaller number of workers demand privately-financed education. This enables individuals to demand more $\left(\partial e_{i}\left(a_{i}, \tilde{a}\right) / \partial \tilde{a}>0\right)$. Migration possibilities increase the individual demand for privately-financed education, owing to the increase in its return, but this increases the price, and thereby it decreases its return and reduces its demand. The former positive effect is completely offset by the latter negative effect (notice that the numerator and the denominator in Equation (2) increase by the same proportion with migration possibilities). Therefore, through this price effect, migration possibilities have no impact on the individual demand for privately-financed education. 
However, I subsequently show that migration possibilities affect the individual demand through another price effect, that is, higher migration possibilities make $\tilde{a}$ smaller (make the number of workers who satisfy the budget constraint larger), leading to the higher price and the lower individual demand for privately-financed education (see the second term on the right-hand side of Equation (7) and Equation (2), or combining these, Equation (8)).

By substituting Equations (3) and (4) into Equation (1) and differentiating the resulting equation with respect to $a_{i}$, I find that net earnings increase with innate ability, $d U_{i} / d a_{i}>0{ }^{11}$ In other words, an individual worker attains higher net earnings if the worker is more innately talented. I assume that the value of $\bar{c}$ is such that $\left.U_{i}\right|_{a_{i}=\varepsilon}<0$ and $\left.U_{i}\right|_{a_{i}=1+\varepsilon}>0$. $^{12}$ Under such an assumption, as we conjectured, the worker with innate ability $a_{i} \in(\widetilde{a}, 1+\varepsilon]$ satisfies the budget constraint with the inequality, $\left.U_{i}\right|_{\widetilde{a}<a_{i} \leq 1+\varepsilon}>0$, and demands privately-financed education; whereas, the worker with innate ability $a_{i} \in[\varepsilon, \tilde{a})$ does not satisfy the budget constraint, $\left.U_{i}\right|_{\varepsilon \leq a_{i}<\widetilde{a}}<0$, and cannot demand privately-financed education.

From Equation (4), the worker with innate ability $\tilde{a}$ demands privately-financed education by

$$
\left.e_{i}\right|_{a_{i}=\widetilde{a}}=\frac{2 \bar{b} \widetilde{a}}{(1+\varepsilon)^{2}-\widetilde{a}^{2}}(\equiv \widetilde{e}(\widetilde{a}))
$$

To illustrate how migration possibilities affect $\widetilde{a}$, I substitute Equations (3) and (5) into Equation (1). From the assumption that $\left.U_{i}\right|_{a_{i}=\widetilde{a}}=0$, I derive

$$
\widetilde{a} w_{H}-\bar{c}-p(\widetilde{a}, \theta) \widetilde{e}(\widetilde{a})+\rho \widetilde{a}\{1+\ln \widetilde{e}(\widetilde{a})\}\left\{\theta w_{F}+(1-\theta) w_{H}\right\}=0 .
$$

Totally differentiating this equation with respect to $\widetilde{a}$ and $\theta$, I derive $A d \widetilde{a}+B d \theta=0$,

where

\footnotetext{
${ }^{11} d U_{i} / d a_{i}=w_{H}+\rho\left[1+\ln 2 \bar{b} a_{i}\left\{(1+\varepsilon)^{2}-\widetilde{a}^{2}\right\}^{-1}\right]\left\{\theta w_{F}+(1-\theta) w_{H}\right\}$.

$\left.{ }^{12} U_{i}\right|_{a_{i}=\varepsilon}=\varepsilon w_{H}+\rho \varepsilon\left[\ln 2 \bar{b} \varepsilon\left\{(1+\varepsilon)^{2}-\widetilde{a}^{2}\right\}^{-1}\right]\left\{\theta w_{F}+(1-\theta) w_{H}\right\}-\bar{c}$.

$\left.U_{i}\right|_{a_{i}=1+\varepsilon}=(1+\varepsilon) w_{H}+\rho(1+\varepsilon)\left[\ln 2 \bar{b}(1+\varepsilon)\left\{(1+\varepsilon)^{2}-\widetilde{a}^{2}\right\}^{-1}\right]\left\{\theta w_{F}+(1-\theta) w_{H}\right\}-\bar{c}$.
} 


$$
\begin{gathered}
A \equiv \frac{\left.\partial U_{i}\right|_{a_{i}=\widetilde{a}}}{\partial \widetilde{a}}=w_{H}-p_{\widetilde{a}} \widetilde{e}(\widetilde{a})+\rho\{1+\ln \widetilde{e}(\widetilde{a})\}\left\{\theta w_{F}+(1-\theta) w_{H}\right\}>0, \\
B \equiv \frac{\left.\partial U_{i}\right|_{a_{i}=\widetilde{a}}}{\partial \theta}=\rho\left(w_{F}-w_{H}\right) \widetilde{a} \ln \tilde{e}(\widetilde{a})>0 .
\end{gathered}
$$

As $\tilde{a}$ is larger, that is, as the number of workers who satisfy the budget constraint is smaller, net earnings are higher $(A>0)$. On the other hand, since higher migration possibilities increase the return on privately-financed education, they increase net earnings by $\rho\left(w_{F}-w_{H}\right) \tilde{a}\{1+\ln \tilde{e}(\tilde{a})\}$, and in contrast, they increase the price and reduce net earnings by $-\rho\left(w_{F}-w_{H}\right) \tilde{a}$. Since the former positive effect outweighs the latter negative effect, higher migration possibilities lead to larger net earnings $(B>0)$.

Accordingly,

$$
\frac{d \widetilde{a}}{d \theta}<0
$$

Therefore, the number of workers who satisfy the budget constraint and demand privately-financed education increases with migration possibilities. This is likely to have a positive effect on the economy's overall human capital formation.

From Equations (3) and (6), migration possibilities increase the equilibrium price of privately-financed education, both directly and indirectly through a decrease in $\tilde{a}$

$$
\frac{d p}{d \theta}=\underbrace{\frac{\partial p(\widetilde{a}, \theta)}{\partial \theta}}_{+}+\underbrace{\frac{\partial p(\widetilde{a}, \theta)}{\partial \widetilde{a}}}_{-} \underbrace{\frac{d \widetilde{a}}{d \theta}}_{-}>0 .
$$

The higher return on privately-financed education increases the individual demand, leading to an increase in the aggregate demand and a higher price. This effect is described by the first term on the right-hand side of Equation (7). In addition, higher migration possibilities increase the number of workers who satisfy the budget constraint, thereby increasing the aggregate demand and price. The second term on the right-hand side of Equation (7) corresponds to this effect.

I determine how migration possibilities affect the equilibrium amount of education for the worker with innate ability $a_{i} \in(\widetilde{a}, 1+\varepsilon]$, utilising Equations (4) and (6)

$$
\frac{d e_{i}}{d \theta}=\underbrace{\frac{\partial e_{i}\left(a_{i}, \widetilde{a}\right)}{\partial \widetilde{a}}}_{+} \underbrace{\frac{d \widetilde{a}}{d \theta}}_{-}<0 .
$$


Higher migration possibilities increase the number of workers who satisfy the budget constraint, which in turn increases the price and reduces the equilibrium amount of privately-financed education for the individual worker. This is likely to have a negative effect on the economy's overall human capital formation.

To summarise, migration possibilities increase the return on privately-financed education and enable more workers to satisfy the budget constraint and demand it. However, at the same time, through price increases, higher migration possibilities lower the return on privately-financed education and reduce such workers' individual demand.

\section{Effects of Migration Possibilities on Average Human Capital}

This section examines how migration possibilities influence the home country's average human capital, that is, whether workers in that country experience brain gain or brain drain, and draws implications for the effect of the labour-receiving countries' restrictive migration policies on the labour-sending countries' human capital formation.

At the end of the first period, the home country's average human capital in terms of efficiency units of labour is equal to

$$
\int_{\varepsilon}^{\widetilde{a}} a_{i} d a_{i}+\int_{\widetilde{a}}^{1+\varepsilon} a_{i}\left\{1+\ln e_{i}\left(a_{i}, \widetilde{a}\right)\right\} d a_{i}\left(\equiv A H C_{1}\right) .
$$

$A H C_{1}$ can be calculated as

$$
\frac{1+2 \varepsilon+\widetilde{a}^{2}-\varepsilon^{2}}{4}+\frac{(1+\varepsilon)^{2}}{2} \ln \frac{2 \bar{b}(1+\varepsilon)}{(1+\varepsilon)^{2}-\widetilde{a}^{2}}-\frac{\widetilde{a}^{2}}{2} \ln \frac{2 \bar{b} \widetilde{a}}{(1+\varepsilon)^{2}-\widetilde{a}^{2}} .
$$

According to Equation (9), migration possibilities affect the average human capital at the end of the first period through changes in the aggregate demand for privatelyfinanced education by workers who satisfy the budget constraint. Regarding this, I derived two opposing effects: a positive effect on the number of workers who actually demand privately-financed education (Equation (6) and a negative effect on individual demand (Equation (8). I infer that the former positive effect increases $A H C_{1}$, whereas the latter negative effect decreases $A H C_{1}$, since 


$$
\frac{d A H C_{1}}{d \theta}=\widetilde{a}\left\{1-\ln \frac{2 \bar{b} \widetilde{a}}{(1+\varepsilon)^{2}-\widetilde{a}^{2}}\right\} \frac{d \widetilde{a}}{d \theta},
$$

I cannot determine in general whether migration possibilities increase or decrease average human capital before migration actually takes place. Higher migration possibilities increase the return on privately-financed education by increasing the possibility to receive higher wages in the foreign country, leading to a larger number of workers who satisfy the budget constraint and demand it. However, migration possibilities also lower the return on privately-financed education by increasing its price, leading to a lower individual demand by an individual worker who satisfies the budget constraint. Moreover, I cannot establish whether the net return on education is positive or negative. As a result, I cannot determine in general whether human capital formation will be encouraged or discouraged with migration possibilities. If the education market did not exist as assumed by previous studies, then the latter negative effect would be nonexistent and workers would always be encouraged to accumulate human capital.

However, if I assume the availability of privately-financed education in the home country, I find that $d A H C_{1} / d \theta<0$ if $\bar{b}$ is small such that $1>\ln \left[2 \bar{b} \widetilde{a} /\left\{(1+\varepsilon)^{2}-\widetilde{a}^{2}\right\}\right]$, and $d A H C_{1} / d \theta>0$ if $\bar{b}$ is large such that $1<\ln \left[2 \bar{b} \tilde{a} /\left\{(1+\varepsilon)^{2}-\widetilde{a}^{2}\right\}\right]$. Accordingly, if the supply of privately-financed education is low, the negative effect dominates and human capital formation will be discouraged by higher migration possibilities. In the opposite case in which the supply is large, the positive effect dominates and human capital formation will be encouraged.

In the second period, $\theta$ of the home country's workers migrate to the foreign country. At the end of the second period, the home country's average human capital is $(1-\theta) A H C_{1}\left(\equiv A H C_{2}\right)$, and the effect of migration possibilities can be expressed as

$$
\frac{d A H C_{2}}{d \theta}=-A H C_{1}+(1-\theta) \frac{d A H C_{1}}{d \theta}
$$

Since higher migration possibilities lower the number of workers who remain in the home country after migration, the average human capital decreases (the first term on the right-hand side of Equation (11). On the other hand, as Equation (10) suggests, higher migration possibilities either encourage or discourage human capital formation in the first period, depending on the size of $\bar{b}$ (the second term on the right-hand side of Equation (11)). Accordingly, it is impossible to determine in general how migration 
possibilities affect the average human capital after migration.

However, if the home country's supply of privately-financed education is low, then Equation (11) suggests that migration possibilities certainly lower the average human capital at the end of the second period. In other words, if the home country cannot sufficiently provide education, then the country experiences brain drain, in the sense that the average human capital reduces after workers leave the country, as the foreign country takes a more positive attitude towards accepting migrants. In my model, if the supply of privately-financed education is limited, higher migration possibilities discourage workers from accumulating human capital (the 'new' type of brain drain) in the first period as well as increase the outflow of workers (the 'conventional' type of brain drain) in the second period. ${ }^{13}$ Accordingly, post-migration average human capital is always lower as workers are more likely to be accepted in the foreign country. In other words, there are no possibilities that workers in the home country experience brain gain after migration has occurred.

This result contrasts with those of previous analyses, according to which brain gain can occur with increases in migration possibilities. It is true that a larger number of workers will have left the home country by the end of the second period, but in their models higher migration possibilities certainly increase the return on education and encourage workers to accumulate human capital in the first period. This is because in their model there is no education market and no negative effect on the return on education due to the increase in the education price.

My results conversely suggest that restrictive migration policies implemented by many labour - receiving developed countries will increase the post-migration average human capital of labour-sending developing countries, in which education is usually inadequately supplied. Under such policies, as I expect, the outflow of workers will be checked and this will prevent the loss of human capital. In addition, unlike previous analyses, individual demand for education by those who can afford it increases, which in turn contributes to human capital formation. This is because in my model the education price decreases with a decrease in migration possibilities. Accordingly, the total positive effects on human capital are greater than the effects that arise only from the smaller outflow of workers.

Therefore, I conclude that labour-receiving developed countries' restrictive attitudes can have a beneficial effect on labour-sending developing countries through brain gain.

\footnotetext{
${ }^{13}$ Of course, this does not mean that the traditional type of brain drain is not important. The new type of brain drain merely enhances the effects of the traditional type of brain drain.
} 
To summarise the results, it is not possible to determine the effect of migration possibilities on the home country's average human capital in general. However, if the home country's supply of education is small, then higher migration possibilities decrease the average human capital after some of the workers in the home country have migrated to the foreign country. This conversely suggests that labour-receiving developed countries' restrictive attitudes towards migrants will generate positive effects on labour-sending developing countries through brain gain.

\section{Concluding Remarks}

Recent studies on migration have indicated the possibility that emigration may have positive impacts on labour-sending countries. In particular, migration prospects may encourage workers in labour-sending countries to build larger human capital. As a result, workers in these countries may experience brain gain as well as brain drain.

Most of these studies implicitly assumed that workers can obtain as much education as they want and that they do not have to pay any pecuniary costs. However, these assumptions are unrealistic. Education cannot be supplied elastically and freely. Many developing countries cannot provide adequate education even in developed countries people pay part or all of the pecuniary costs of tertiary education. Moreover, there is a growing trend of increasing competitiveness in education markets. Given these facts, the paper assumed that the supply of education is not necessarily large, workers pay the pecuniary cost for education and its price is determined competitively in the education market. Most importantly, I assumed that they have to satisfy the budget constraint to demand education.

The paper found that migration possibilities increase the number of workers who demand education, but they reduce such workers' individual demand for education. Based on this, I found that the home country's average human capital decreases with migration possibilities if that country cannot sufficiently supply privately-financed education. Therefore, I infer that restrictive migration policies adopted by labourreceiving countries increase the post-migration average human capital of labour-sending countries in which the supply of education is insufficient.

We expect that restrictive migration policies of labour-receiving countries will reduce the number of emigrants from labour-sending countries, and this in turn 
alleviates the outflow of human capital. However, in my analyses, positive effects of such policies also come from increases in human capital formation due to the higher return on education. This is in marked contrast with results of previous analyses, according to which lower migration possibilities discourage workers from accumulating human capital. These differences are associated with the existence or non-existence of the education market and the effects of the education price on its demand.

Today, labour-receiving developed countries are becoming restrictive and selective in accepting migrants, and this situation is expected to continue. In addition, laboursending developing countries will be unable to overcome the insufficient provision of education easily. I attempted to clarify how these trends affect labour-sending developing countries. Contrary to our intuition, the results derived in this paper suggest that these circumstances are not completely harmful to these countries.

Competitiveness of the education market, the private financing of education and a lack of an intergenerational relationship were assumed for the purpose of simplicity. My analysis can be extended by relaxing these assumptions.

Received 06 December 2012, Revised 02 July 2013, Accepted 05 July 2013

\section{References}

Australian Government (2011), "SkillSelect", Department of Immigration and Citizenship, Australian Government, at http:/www.immi.gov.au/skilled/general-skilled-migration/skillselect.htm, accessed on 5 December 2011.

Barr, N. (2004), "Higher Education Funding”, Oxford Review of Economic Policy, Vol. 20, pp. 264-283.

Beine, M., Docquier, F., Rapoport, H. (2001), "Brain Drain and Economic Growth: Theory and Evidence", Journal of Development Economics, Vol. 64, pp. 275-289.

Beine, M., Docquier, F., Rapoport, H. (2008), "Brain Drain and Human Capital Formation in Developing Countries: Winners and Losers”, Economic Journal, Vol. 118, pp. 631-652.

Beine, M., Docquier, F., Oden-Defoort, C. (2011), “A Panel Data Analysis of the Brain Gain”, World Development, Vol. 39, pp. 523-532.

Berry, R. A., Soligo, R. (1969), “Some Welfare Aspects of International Migration”, Journal of Political Economy, Vol. 77, pp. 778-794.

Bhagwati, J., Hamada, K. (1974), “The Brain Drain, International Integration of Markets for Professionals and Unemployment: A Theoretical Analysis”, Journal of Development Economics, Vol. 1, pp. 19-42.

Bhagwati, J., Rodriguez, C. (1975), "Welfare-Theoretical Analyses of the Brain Drain”, Journal of Development Economics, Vol. 2, pp. 195-221. 
Boeri, T., Brücker, H. (2005), "Why Are Europeans So Tough on Migrants?", Economic Policy, Vol. 20, pp. 629-703.

Docquier, F., Marfouk, A. (2006), "International Migration by Educational Attainment, 1990-2000". In International Migration, Remittances, and the Brain Drain, ed. Ç. Özden, M. Schiff, 151-200. Washington DC: The World Bank and Palgrave Macmillan.

Docquier, F., Rapoport, H. (2009). "Skilled Immigration: The Perspective of Developing Countries". In Skilled Immigration Today: Prospects, Problems, and Policies, ed. J. Bhagwati, G. Hanson, 247-284. Oxford: Oxford University Press.

Facchini, G., Mayda, A. M. (2008), "From Individual Attitudes towards Migrants to Migration Policy Outcomes: Theory and Evidence", Economic Policy, Vol. 23, pp. 651-713.

Felbermayr, G., Geis, W., Kohler, W. (2010), "Restrictive Immigration Policy in Germany: Pains and Gains Foregone?", Review of World Economics, Vol. 146, pp. 1-21.

Grogger, J., Hanson, G. H. (2011), "Income Maximization and the Selection and Sorting of International Migrants", Journal of Development Economics, Vol. 95, pp. $42-57$.

Grubel, H. B., Scott, A. D. (1966), "The International Flow of Human Capital”, American Economic Review, Vol. 56, pp. 268-283.

Hamada, K., Bhagwati, J. (1975), "Domestic Distortions, Imperfect Information and the Brain Drain", Journal of Development Economics, Vol. 2, pp. 265-279.

Huber, P., Landesmann, M., Robinson, C., Stehrer, R. (2010), "Migrants' Skills and Productivity: A European Perspective", National Institute Economic Review, Vol. 213, pp. R20-R34.

Mountford, A. (1997), "Can a Brain Drain Be Good for Growth in the Source Economy?", Journal of Development Economics, Vol. 53, pp. 287-303.

Nakajima, T., Nakamura, H. (2009), “The Price of Education and Inequality”, Economics Letters, Vol. 105, pp. 183-185.

Shimada, A. (2010), "The Transfer of the Remittance Fee from the Migrant to the Household", Journal of Economic Integration, Vol. 25, pp. 613-625.

Shimada, A. (2011a), "The Role of Altruism in Sending and Spending Remittances", Journal of East Asian Economic Integration, Vol. 15, pp. 61-82.

Shimada, A. (2011b), "Wage Inequality and Human Capital Formation". Paper presented at the 10th Annual Meeting of the European Economics and Finance Society held at Queen Mary, University of London in June 2011; the 2011 Asian Meeting of the Econometric Society held at Korea University in August 2011; and the 2011 Autumn Meeting of the Japanese Economic Association held at University of Tsukuba in October 2011.

Stark, O., Helmenstein, C., Prskawetz, A. (1997), “A Brain Gain with a Brain Drain”, Economics Letters, Vol. 55, pp. 227-234.

Stark, O., Helmenstein, C., Prskawetz, A. (1998), "Human Capital Depletion, Human Capital Formation, and Migration: A Blessing or a 'Curse'?”, Economics Letters, Vol. 60, pp. 363-367.

Stark, O., Casarico, A., Uebelmesser, S. (2009a), "An Optimal Selective Migration Policy in the Absence of Symmetric Information, and in the Presence of Skill Formation Incentives". In Corruption, Development and Institutional Design, ed. J. Korani, L. Mátyás, and G. Roland, 152-168. New York: Palgrave Macmillan. 
Stark, O., Casarico, A., Devillanova, C., Uebelmesser, S. (2009b), "International Migration, Human Capital Formation, and the Setting of Migration-Control Policies: Mapping the Gains". In Corruption, Development and Institutional Design, ed. J. Korani, L. Mátyás, and G. Roland, 169-186. New York: Palgrave Macmillan.

World Bank (2000), Higher Education in Developing Countries: Peril and Promise. Published for the Task Force on Higher Education and Society. Washington DC: The World Bank.

World Bank (2011), Migration and Remittances: Factbook 2011, 2nd edition. Washington DC: The World Bank. 